\title{
Le monde complexe des angiotensines
}

Tout d'abord, un nouveau venu : l'angiotensine-(1-7), un heptapeptide qui se distingue de l'angiotensine II par la perte de la phénylalanine en position 8, à l'extrémité C-terminale. Le groupe de C. M. Ferrario, à la Cleveland Clinic (OH, USA), qui est à l'origine de cette découverte, vient d'identifier l'angiotensine-(1-7) dans le plasma de chiens normaux et binéphrectomisés, mais à une concentration plus faible chez ces derniers. L'administration d'un inhibiteur de l'enzyme de conversion diminue, comme prévu, les taux plasmatiques d'angiotensine II et augmente non seulement les concentrations d'angiotensine I, mais aussi celles d'angiotensine-(1-7) [1]. Dans des travaux précédents, le même groupe avait montré que l'angiotensine-(1-7) stimule la libération de vasopressine et "module" la sensibilité du baroréflexe [2], avec une puissance équivalente à celle de l'angiotensine II. L'angiotensine-(1-7) se lie aux récepteurs qui reconnaissent l'angiotensine II, et ces deux peptides se déplacent l'un l'autre du site de fixation [3].

Ces résultats sont surprenants car, jusqu'à présent, on considérait que le clivage de l'extrémité C-terminale de l'angiotensine II aboutissait à la création de fragments inactifs. En revanche, on sait depuis longtemps que le clivage de l'acide aspartique, en position 1, à l'extrémité N-terminale, conduit à la formation de l'angiotensine III qui se lie au même récepteur que l'angiotensine II et exerce des effets biologiques, notamment dans la stimulation de la sécrétion d'aldostérone [3].

L'utilisation d'antagonistes non peptidiques (donc actifs par voie orale) du récepteur de l'angiotensine II vient d'apporter récemment des informations intéressantes sur l'hétérogénéité de ce récepteur [4]. En effet, un antagoniste comme le $\mathrm{Du}$ P753 déplace environ $80 \%$ de la liaison de l'angiotensine II à des microsomes cortico-surrénaliens alors qu'un autre antagoniste, le PD 123177, ne déplace que $20 \%$, à des concentrations micromolaires. En revanche, la saralasine, un antagoniste peptidique de l'angiotensine II, induit un déplacement complet de l'angiotensine. Sur d'autres tissus, comme le muscle lisse vasculaire, la saralasine et le Du P753 exercent les mêmes effets.

Il semble donc exister deux types de site de liaison de l'angiotensine II qui se distribuent irrégulièrement selon les tissus : $\mathrm{AII}_{1}$ inhibé par Du P753 à des concentrations de l'ordre de la nanomole, et $\mathrm{AII}_{2}$ représentant $20 \%$ des sites totaux, inhibé sélectivement par PD 123177. Du P753 est 10000 fois plus sélectif pour $\mathrm{AII}_{1}$ et PD 123177, 3500 fois plus sélectif pour $\mathrm{AII}_{2}$. Au contraire, la saralasine n'a pas de sélectivité. L'angiotensine III a un peu plus d'affinité pour $\mathrm{AII}_{1}$ que pour $\mathrm{AII}_{2}$.

Les antagonistes précédents se comportent comme des antagonistes com- pétitifs. Une autre substance, EXP 3892, se révèle être un antagoniste non compétitif (" insurmontable ") : sur l'aorte de lapin, ce produit réduit de $60 \%$ la réponse maximale à l'angiotensine II ; au contraire, DuP 753 ne modifie pas la réponse maximale mais déplace la courbe concentration-réponse vers la droite. Fait remarquable, l'addition de DuP 753 à EXP 3892 restaure la réponse maximale. L'explication de ce phénomène reste encore incertaine [4].

Après les inhibiteurs de l'enzyme de conversion puis les inhibiteurs de la rénine [5], les antagonistes non peptidiques du récepteur de l'angiotensine II sont un nouvel outil pharmacologique et, peut-être, une nouvelle classe thérapeutique.

J.P. G.

1. Kohara K, Brosnihan KB, Chappell MC, et al. Angiotensin-(1-7): a member of circulating angiotensin peptides. Hyperlension $1991 ; 17: 131-8$

2. Ferrario CM, Ueno Y, Diz DJ, et al. Pathways of angiotensin formation and function in the brain. Hyperlension $1990 ; 15$ (suppl 1) : 113-9.

3. Goodfriend TL. Angiotensins : a family that grows from within. Hypertension 1991; 17 : $139-40$.

4. Timmermans PBMWM, Wong PC, Chiu AT, el al. Nonpeptide angiotensin II receptor antagonists. Trends Pharmacol Sci 1991; $12: 55-62$

5. Corvol P, Chauveau D, Jeunemaître X, et al. Human renin inhibitor peptides. Hyperlension $1990 ; 16: 1-11$

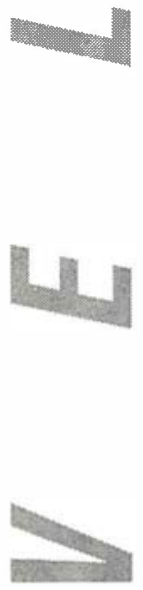

